\title{
Palabras de bienvenida
}

\author{
Welcoming remarks
}

Alvaro Pereira Delgado · Servicio de Asistencia Religiosa de la Universidad de Sevilla

https://doi.org/10.17979/aarc.2013.3.0.5077

Estimadas autoridades, estimados profesores organizadores del congreso, estimados alumnos y alumnas:

Saludo con gran alegría la celebración de este III Congreso Internacional de Arquitectura Religiosa Contemporánea en nuestra ciudad de Sevilla. Nos sentimos muy honrados de que hayan venido arquitectos, teólogos y especialistas de tantos sitios para participar activamente de este evento.

En nombre del arzobispo, Mons. Juan José Asenjo Pelegrina, les doy la bienvenida y nos ponemos a vuestra disposición. Desde el SARUS, Servicio de Asistencia Religiosa de la Universidad de Sevilla, órgano que intenta suscitar el diálogo entre la fe cristiana y la cultura universitaria, recibimos con especial alegría este congreso, tanto desde el punto de vista universitario, como eclesial.

El mundo universitario, por un lado, tiende hoy hacia una especialización extrema. Debemos reconocer que nuestra universidad actual se parece poco a aquella «universitas» medieval de profesores y estudiantes que buscaban juntos la verdad en todos los saberes, o como diría Alfonso $X$ el Sabio, ese «ayuntamiento de maestros y escolares con voluntad y entendimiento de apren- der los saberes» (Siete Partidas, partida II, tít. $X X X I)$. Por eso, este tipo de congresos, donde se ponen en diálogo disciplinas diversas, es una verdadera buena noticia.

Desde el punto de vista eclesial, por otro lado, este congreso es una extraordinaria oportunidad para dar pasos en nuevos modos de evangelización. Debo decir con tristeza que es común entre sacerdotes y fieles la idea de que la arquitectura contemporánea no termina de ofrecer espacios adecuados para elevar el espíritu humano y suscitar devoción. Pero les confieso también que tengo un hermano arquitecto, que me ha hecho ver en varias ocasiones cómo los sacerdotes afeamos y arruinamos un proyecto interesante, por nuestra poca formación arquitectónica. Se impone, por tanto, un diálogo fecundo y franco que geste una arquitectura ideal, como aquella deseada por Walter Gropius: «la expresión cristalina de los más nobles pensamientos del hombre, de su ardor, de su humanidad, de su fe, de su religión».

Puesto que el congreso se centra en las arquitecturas efímeras, me gustaría que supieran, estimados congresistas, que llegan a una ciudad experta en elevar soberbios altares fugaces para celebraciones litúrgicas. Gloriosa fue la máquina 


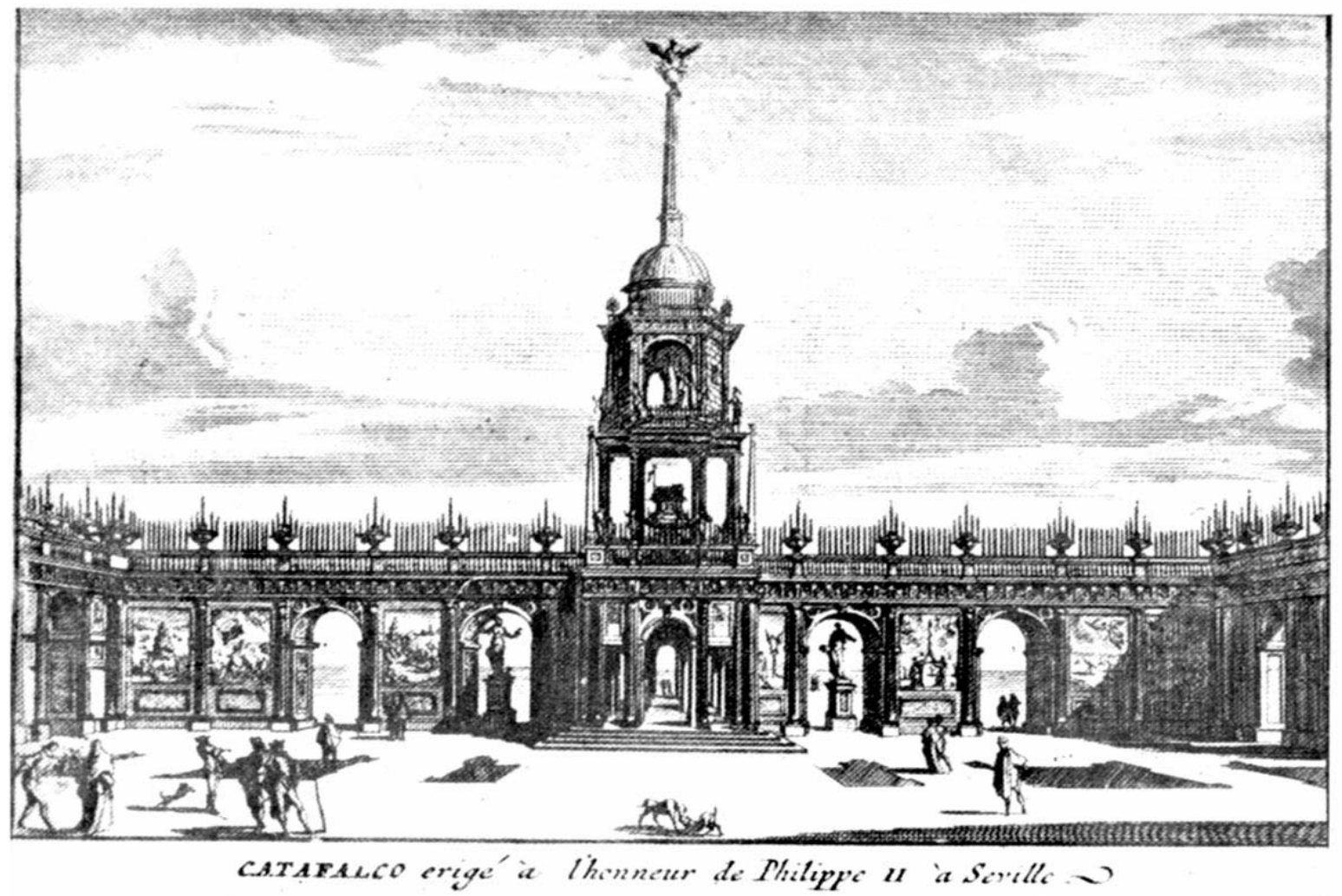

Fig. 01. Andrés García de Urías, Túmulo para las exequias del rey Felipe II, Sevilla, 1589.

barroca edificada en 1671 para solemnizar la concesión a la ciudad de Sevilla de la celebración de la misa ritual de la Inmaculada Virgen María. O más célebre aún fue el túmulo que se edificó junto a la catedral de Sevilla para las exequias de Felipe II en 1589 (Fig. 01), y que inspiró el famoso soneto con estrambote de Miguel de Cervantes. Os lo recito porque en él se capta una de las ideas más interesantes de la arquitectura efímera religiosa: mostrar la belleza de la fe pero, al mismo tiempo, significar la fugacidad de nuestras construcciones humanas.

Voto a Dios que me espanta esta grandeza y que diera un doblón por describilla, porque ¿a quién no sorprende y maravilla esta máquina insigne, esta riqueza?
Por Jesucristo vivo, cada pieza vale más de un millón, y que es mancilla que esto no dure un siglo, ioh gran Sevilla!, Roma triunfante en ánimo y nobleza.

Apostaré que el ánima del muerto por gozar este sitio hoy ha dejado la gloria donde vive eternamente.

Esto oyó un valentón y dijo: «Es cierto cuanto dice voacé, señor soldado. $Y$ el que dijere lo contrario, miente.»

Y luego, incontinente, caló el chapeo, requirió la espada miró al soslayo, fuese y no hubo nada. 
Esta tradición de las arquitecturas efímeras continúa hoy. Les invito a venir la víspera del Corpus Christi, quizás uno de los días más bellos de la ciudad de Sevilla, donde se montan decenas de altares efímeros por las calles, algunos de los cuales superan los cuatro pisos del altura.

Parecería que la arquitectura efímera hoy es una solución práctica para responder a la realidad de las multitudes (Jornadas Mundiales de la Juventud, congresos sobre la familia, etc.). Parecería que los arquitectos deberían consultar a los teólogos para lograr que no se diluyera la identidad cristiana y litúrgica de esta clase de altares provisionales. Pero quizás no solo los arquitectos deban ser solicitados por los teólogos para lograr que sus construcciones sean más evocadoras del Misterio e inspiradoras de la fe. También la Iglesia puede recibir nuevas intuiciones y mociones de estas arquitecturas efímeras que evidencian algunos rasgos eclesiales a veces olvidados:

-Estas construcciones provisorias, realizadas fuera de los recintos sacros, nos recuerdan que la muerte de Cristo rasgó el velo del templo y declaró abolidas las distinciones entre los espacios sagrados y los espacios sagrados. En este sentido, la constante llamada del papa Francisco a «salir» al encuentro de las periferias existenciales del hombre son un acicate a descubrir la presencia sagrada de Dios en ámbitos que podrían parecer ajenos a ella.

-En segundo lugar, las arquitecturas efímeras, realizadas con frecuencia al aire libre, nos evo- can una intuición de los profetas de Israel que, tras el destierro, descubrieron como todo era creación de Dios. «Así dice el Señor: «Los cielos son mi trono y la tierra estrado de mis pies, ¿qué casa me vais a edificar o qué lugar para mi reposo, si el universo lo hizo mi mano y todo vino al ser?» (Is 66, 1-2).

-Por último, apuntan a la provisionalidad y la finitud de todas nuestras realizaciones humanas. ¿Acaso Abraham no habitó en tiendas, peregrinando hacia la Tierra prometida, ansiando la ciudad asentada sobre cimientos, cuyo arquitecto y constructor es Dios? (cf. Heb 11, 9-10). ¿Acaso no fue el mismo Dios quien prefirió habitar en la tienda del encuentro, otra arquitectura efímera, que recordaba a los israelitas su identidad de pueblo peregrino?

iQué buena definición de los cristianos!: Peregrinos que realizan construcciones provisionales, sabiendo que su única edificación eterna es la ciudad de sólidos fundamentos, ila Jerusalén de arriba!

Me gustaría terminar esta intervención dando las gracias al profesor Pablo Millán, auténtica alma mater de este congreso, al magnífico Comité Científico y al resto de instituciones que han hecho posible con su patrocinio este evento que, en tiempos de economías -nunca mejor dicho"efímeras», se ha abierto paso a través de muchas tempestades.

Les saludo y les deseo unos magníficos días en nuestra ciudad. 
PALABRAS DE BIENVENIDA

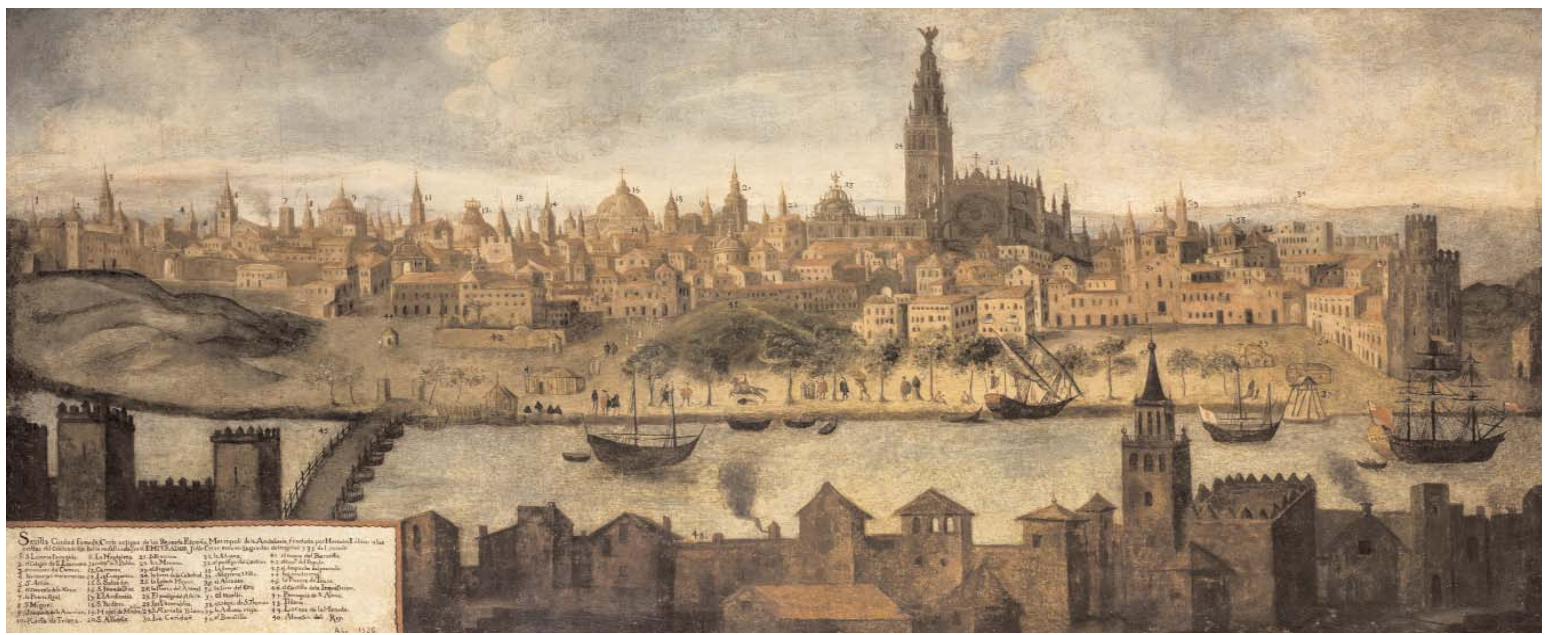

